\title{
Mentorship: the heart and soul of health care leadership
}

This article was published in the following Dove Press journal:

Journal of Healthcare Leadership

22 April 2010

Number of times this article has been viewed

\author{
Joellen W Hawkins' \\ Holly B Fontenot ${ }^{2}$ \\ 'William F Connell School of Nursing, \\ Boston College, Auburndale, MA, USA; \\ ${ }^{2}$ William F Connell School of Nursing, \\ Boston College, Chestnut Hill, MA, \\ USA
}

\begin{abstract}
The key to the development of leaders for the health care professions is mentoring. Both leaders and mentors need to develop their own self-knowledge, strategic visions for their own careers, engage in risk-taking, express creativity through all aspects of their lives, feel inspired and inspire others. Communication is central to a positive mentoring relationship and a successful role in a health care leadership position. Thus, when neophyte health care leaders have the opportunity to be mentored, the development of good communication skills will benefit them in their future leadership positions. An important gift health care leaders can give to their professions is to serve as mentors for those who will lead health care organizations and institutions into the next decades. In this article, the authors will discuss the mentoring role integral to assuming leadership roles and present a number of models for mentoring programs in the health care professions.
\end{abstract}

Keywords: mentor, mentee, mentoring programs

\section{Introduction}

The headline of an article by White in the American Journal of Health-System Pharmacy reads "will there be a pharmacy leadership crisis?" Leatt and Porter ${ }^{2}$ wrote of the crisis in health care leadership, citing the need for a unique model for preparing leaders for health care organizations and institutions. "Mentoring the next generation of leaders in health professions is the responsibility of the current generation." As Owens and Patton ${ }^{3}$ observed, "mentorships build leaders." Bickel and colleagues ${ }^{4}$ included examples of mentoring programs for women in medicine and noted these are essential for women to have parity with men in academic center leadership positions. Although some mentoring programs do exist: physicians; nurses; physical and occupational therapists; dieticians; veterinarians; dentists; pharmacists; psychologists; social workers; and other health professionals assume their first leadership positions often with some trepidation and angst, less than optimal orientation periods, and no formal mentoring. ${ }^{2}$

The purpose of this article is present some exemplars of mentoring programs designed to prepare leaders who come from clinical backgrounds and to discuss the characteristics of mentors and the mentoring experiences within the health professions.

\section{Exemplars of mentoring programs in the health professions}

The roles of health care professionals as leaders can be many and varied, increasing the need for neophytes to have opportunities for mentoring. In an effort to increase the 
number of women in leadership positions in academic medical centers, the Association of Academic Medical Centers created a mentoring program for women. ${ }^{4}$ This program is modeled on the Association's program to prepare physicians for leadership positions in academic medical centers, ${ }^{5}$ The US Centers for Disease Control and Prevention sponsors a formal mentorship program for public health advisors, one of its strategies for developing new CDC program managers. ${ }^{6}$

Numerous professional organizations offer mentoring programs. The American Dental Education Association, recognizing the dearth of women in executive positions and serving as deans of dental schools, in 1992, created a program of women liaison officers (WLOs) appointed by dental school deans. One of the roles of these WLOs is mentorship to foster women's preparation for leadership positions in dental education. ${ }^{?}$

The Fellows of the American Academy of Nurse Practitioners (AANP) have a formal mentoring program. ${ }^{8}$ Members of the Academy can apply to have a mentor, stating the purpose and goals for the mentoring experience and identifying characteristics of the desired mentor. A mentee who holds a leadership position in the Department of Veterans Affairs might request a nurse leader in the Department of Veterans Affairs or in another large health care system.

The American Psychological Association (APA) offers a number of mentoring programs within its divisions and committees. Chao ${ }^{9}$ described this mentoring program including criteria for matching mentors and mentees, training the program participants, and resources available to them. ${ }^{10}$ She reported on lessons learned from the pilot program: the matching process is critical to the success of the mentoring; successful matches require a large pool of potential mentors; the choice on the part of both mentors and mentees is important; requiring that individuals be specific about their priorities for matching; and careful oversight of the reviewing process for participants in the mentoring program. ${ }^{9}$

Reporting on a study of mentoring of individuals holding positions as school or college psychologists, Swerdick and Bardon ${ }^{11}$ noted that some of the respondents were in leadership positions within their institutions. These mentees noted the benefits of mentoring in their career development. Consonant with these findings highlighting psychologists in leadership positions, Belar ${ }^{12}$ detailed the positions psychologists hold in capitated care systems including serving as administrators. In a discussion of emerging models of health care delivery, Broslowski ${ }^{13}$ urged that graduate programs in psychology include information on the organization and delivery of services to patients. Thus, the mentoring program under the auspices of the APA is of particular importance for its members who aspire to leadership positions in health care.

Leaders in health professions are often expected to be mentors to other less experienced leaders or managers in their organizations or institutions. But who mentors these leaders as they develop and who prepares them to assume mentoring as one of the many responsibilities often thrust upon leaders? McCloughen and colleagues ${ }^{14}$ addressed these issues in their study. The focus was on the mentoring of leaders in nursing. They pointed out that mentoring has a value beyond the production of good leaders - for it contributes to nurse recruitment and retention and also to the development of future leaders. According to these authors, the characteristics of great mentors for leadership include being a visionary, being highly cognizant of the "professional landscape, politically astute, cognizant of health culture, and sensitive to the ebbs and flows of human life."14

\section{Ideal mentor characteristics for the health care professions}

Formal mentoring programs for leaders in the health professions are based on the premise that mentor and mentee choose to enter into a mentoring relationship. The two parties agree on the goals for the mentorship and work together toward those goals. Mentorships may last the lifetime of the individuals, but most are of a mutually delineated duration.

Dracup and Bryan-Brown ${ }^{15}$ cited the core competencies of the Robert Wood Johnson Nurse Fellows Program as those both leaders and mentors should possess: self-knowledge; strategic vision; risk-taking and creativity; interpersonal and communication effectiveness; and inspiration. Mentors can possess the best of some or all of these characteristics, yet how they express these characteristics in their interactions with their mentees is key to their effectiveness. These core competencies are important to leaders in all health professions.

\section{Styles of mentors}

Mentors' styles are as varied as the persons who choose careers as health professionals. Some mentors appear to have a philosophy of mentoring that one can best characterize as trial by fire or critical, and others appear to have more nurturing styles. Both styles can either be effective or a hindrance for a mentee. The key is to find the right match between mentor and mentee that will be beneficial to both parties.

Mentors who are toxic can do more harm than good for their mentees. Darling ${ }^{16}$ noted four categories of toxic mentors: avoiders who are seldom if ever available and 
impossible to reach; dumpers who believe in the sink or swim approach to surviving as professionals; blockers who either micromanage or withhold information; and destroyers whose goal seems to be to undermine anything and everything the mentee proposes. The trial-by-fire mentors may bombard their mentees with criticisms of their work in the extreme. The underlying philosophy appears to be that such hazing will toughen the mentees up for the real world of academia or clinical practice or whatever the field and role for which the mentee is preparing.

$\mathrm{Chao}^{9}$ detailed positive criteria used to match mentors and mentees for the pilot mentoring project of the APA. Experience and expertise included: role modeling; general support; life balance in work; parenting, and managing a career; networking and how to do research and procure grants; achieve tenure; publish; and start one's own practice. Another criterion for APA mentors is experience with challenges such as race, sex, sexual orientation, disability, and religion. ${ }^{9}$

Barker ${ }^{17}$ described what she termed successful mentoring as a relationship wherein the mentor communicates with, rather than talking at the mentee. Setting objectives for the relationship is extremely important to its success. So is feeling out the relationship before making a commitment. The styles of the mentor and the mentee can either make or break the relationship. ${ }^{17}$

Most important to the success of a mentoring relationship is to clarify the roles of each, mentor and mentee, and the goals for the mentorship. Setting time limits may also be helpful in structuring the work to be accomplished. Williams-Nickelson ${ }^{18}$ described an investigation of a mentoring model for professional psychology, derived from a pilot study with 55 women graduate students throughout the US and interviews with women well known in the field. Her participants emphasized the need for a clear understanding of the purpose of the mentoring relationship and the roles of both mentor and mentee. The most effective mentoring relationships occur naturally rather than being set up by another. Steps in establishing the mentoring relationship are: 1) formation - making a commitment and sharing knowledge; 2) establishing the relationship, setting boundaries and defining standards of excellence within the mentor's areas of expertise; and 3) managing and maintaining the mentoring relationship. ${ }^{18}$

Barker $^{17}$ in addressing mentoring, described what she termed a "dynamic and complex relationship that can support growth, increase synergy, improve professional growth, competency, and productivity." She continued: expectations of the protégé may also include the ability to listen to constructive suggestions and reshape behaviors."17
Hayes ${ }^{19}$ noted that mentoring is a "voluntary, intense, committed, extended, dynamic, interactive, supportive, trusting relationship between two people, one experienced, and the other a newcomer, characterized by mutuality." The goals of a mentoring experience, according to Hayes' research, are accomplished through "teaching, socializing, providing opportunity, sponsoring, coaching, guiding, protecting, advising and counseling, encouraging, inspiring, challenging, role modeling, supporting and befriending." 19

$\mathrm{Chao}^{9}$ described the characteristics of the resulting mentoring relationships through the evaluation of the APA pilot program: mismatched; needs of mentee not related to the experiences of the mentor; time constraints and other demands interfered with maintaining the relationship; mentors who made the effort to contact their mentees regularly and to provide support; connecting mentees with resources; and helpful in defining career goals.

\section{Concluding thoughts}

Although the origins of the meaning of the word mentor, attributed to Homer in the Odyssey, are at best mired in classical interpretations, mentor eventually came to mean a role model, teacher, sponsor, coach, guide, advisor, counselor, inspiring leader, an "esteemed connection."

Mentoring relationships are sometimes deliberate, set up within health care agencies and institutions or professional organizations. They can also evolve spontaneously, as a connection is forged between two individuals with complementary skills, attributes, and goals. These relationships exist within the walls of institutions or halfway around the globe. Hayes ${ }^{21}$ wrote, "It would be ideal if potential mentors and mentees lived in the same geographic area. If not, technology can help to bring together people willing to take a risk."

From the literature, it is apparent that mentoring programs can be very valuable to health professionals assuming leadership roles. Careful planning, with special attention to the matching process, can help both mentors and mentees circumvent the potholes in the road to successful and helpful mentoring experiences. As Chao ${ }^{9}$ reported, "both participants in a mentor-mentee pair have to be committed to the relationship. The motivation and commitment required for a successful mentorship can be enhanced with good training and program support." Most important to the mentoring role is a passing of the torch, mentor to mentee, so that the mentee, in time, will take on the role of mentor to colleagues much younger in their professional lives. 


\section{Disclosure}

The authors report no conflicts of interest in this work.

\section{References}

1. White SJ. Will there be a pharmacy leadership crisis? An ASHP Foundation Scholar-in-Residence report. Am J Health Syst Pharm. 2005:62:845-855.

2. Leatt P, Porter J. Where are the healthcare leaders: The need for investment in leadership development. Healthc Pap. 2003;4:14-31.

3. Owens JK, Patton JG. Enhance leadership with this win-win strategy. Nurs Educ Perspect. 2003;24:198-204.

4. Bickel J, Wara D, Atkinson BF, et al. Increasing women's leadership in academic medicine: Report of the AAMC project implementation committee. Acad Med. 2002;77:1043-1061.

5. Morahan PS, Kasperbauer D, McDade SA, et al. Training future leaders of academic medicine: Internal programs at three academic health centers. Acad Med. 1998;73:1159-1168.

6. Watsonian Society. An organization for public health advisors. Mentor program. Available from: http://www.cdc.gov/Watsonian/Mentor.HTM Accessed 2010 February 18.

7. Sinkford JC, Valachovic RW, Harrison S. Advancement of women in dental education: Trends and strategies. J Dent Educ. 2003;67:79-83.

8. American Academy of Nurse Practitioners. FAANP mentoring program. Available from: http://www.aanp.org/AANPCMS2/MemberCenter/ Fellows + Program $+($ FAANP)/MentoringProgram/. Accessed 2010 January 30 .

9. Chao GT. Formal mentoring: Lessons learned from past practice. Prof Psychol Res Pr. 2009;40(3):314-320.
10. American Psychological Association. Introduction to Mentoring: A Guide for Mentors and Mentees. Washington, DC: APA; 2006.

11. Swerdick ME, Bardon JI. A survey of mentoring experiences in school psychology. J Sch Psychol. 1988;26(3):213-224.

12. Belar CD. Collaboration in capitated care: Challenges for psychology. Prof Psychol Res Pr. 1995;26(2):139-146.

13. Broslowski AT. The evolution of healthcare: Implications for the training and careers of psychologists. Prof Psychol Res Pr. 1995;26(2):156-162.

14. McCloughen A, O'Brien L, Jackson D. (2009). Esteemed connection: Creating a mentoring relationship for nurse leadership. Nurs Inq. 2009;16(4):326-336.

15. Dracup K, Bryan-Brown CW. From novice to expert to mentor: Shaping the future. Am J Crit Care. 2004;13:448-450.

16. Darling LW. What to do about toxic mentors. J Nurs Adm. 1985;14:43-44.

17. Barker ER. Mentoring - a complex relationship. J Am Acad Nurse Pract. 2006;18:56-61.

18. Williams-Nickelson C. Mentoring women graduate students: A model for professional psychology. Prof Psychol: Res Pra. 2009;40(3):284-291.

19. Hayes EF. Mentoring and nurse practitioner student self-efficacy. WJNR. 1998;20(5):521-525.

20. Barondess JA. On mentoring. J R Soc Med. 1997;90:347.

21. Hayes EF. Approaches to mentoring: How to mentor and be mentored. J Am Acad Nurse Pract. 2005;17:442-445.
Journal of Healthcare Leadership

\section{Publish your work in this journal}

The Journal of Healthcare Leadership is an international, peer-reviewed, open access journal focusing on leadership for the health profession. The journal is committed to the rapid publication of research focusing on but not limited to: Healthcare policy and law; Theoretical and practical aspects healthcare delivery; Interactions between healthcare and society and evidence-based practices;

\section{Dovepress}

Interdisciplinary decision-making; Philosophical and ethical issues; Hazard management; Research and opinion for health leadership; Leadership assessment. The manuscript management system is completely online and includes a very quick and fair peer-review system. Visit http://www.dovepress.com/ testimonials.php to read real quotes from published authors. 